\title{
Comparitive Study on Antibacterial Activity of Crude and Silver Nanoparticles Synthesized Leaf Extract of Carica papaya against Chosen Isolates
}

\author{
Pandiarajan. P. ${ }^{a}$, Andrew Pradeep. M..$^{a} *$, Januja J. ${ }^{a}$, Dhurairaj Satheesh ${ }^{b}$ \\ a PG Department of Microbiology, The American College, Madurai, Tamil Nadu, India. \\ ${ }^{b}$ PG and Research Department of Chemistry, Loganatha Narayanasamy Government College (Autonomous), Ponneri-601 204, \\ Tamilnadu, India. \\ *Corresponding author's E-mail: micpradeep@gmail.com
}

Received: 10-06-2021; Revised: 21-08-2021; Accepted: 27-08-2021; Published on: 15-09-2021.

\begin{abstract}
The Emergence of Human Pathogens with Antibiotic resistance genes has shifted the focus towards the plant origin antimicrobial drugs with advanced nano-based methods. Screening of phytochemical components is done using various biochemical methods. UVvisible spectrophotometer is utilized to determine the silver Nanoparticle's size, shape, and its stable nature in the aqueous colloidal solution. FT-IR spectral analysis to identify the bio molecules responsible for the reduction of $\mathrm{Ag}^{+}$ions. The extracts of Carica papaya leaves were found to be rich in Vitamins, Phenols, Proteolytic enzymes which acts as excellent Antimicrobial agent. Antibacterial activity of crude extracts and silver Nanoparticles synthesized from Carica papaya leaves was evaluated against chosen clinical isolates, which shows the effective zone of inhibition lesser side effects. Though crude extract has shown significant results, silver nanoparticles synthesized using specific key phytochemical component would have the better inhibiting capacity.
\end{abstract}

Keywords: Carica papaya; Antibacterial activity; Plant extract; FT-IR study; silver Nanoparticles.

QUICK RESPONSE CODE $\rightarrow$

DOI:

10.47583/ijpsrr.2021.v70i01.021

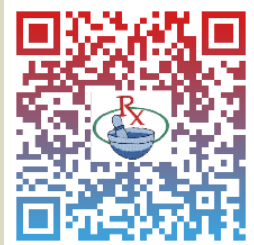

DOI link: http://dx.doi.org/10.47583/ijpsrr.2021.v70i01.021

\section{INTRODUCTION}

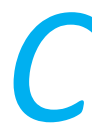

aricaceae family is best known for its medicinal remediation, one of the significant medicinal value species is Carica papaya ${ }^{1}$. Silver Nanoparticles have a long and intriguing history as an antibiotic in human health care ${ }^{2}$. Silver ion is biologically active and readily interacts with proteins, amino acids reside, free anions and receptors on mammalian and eukaryotic cell membrane. Hybrids of silver Nanoparticle with amphiphilic hyper branched macromolecule exhibits effective antimicrobial surface coating agent ${ }^{3}$. Aqueous extracts of Carica papaya leaves rich in phenol, proteolytic enzymes, which act as excellent antimicrobial agent ${ }^{4}$. The Carica papaya leaf extract mediated synthesis of silver Nanoparticle was effective and provides additional property such as bactericidal efficient and might act as long searched alternative and could be the answer to antibiotic resistance 4 .

The silver nanoparticles showed efficient biological property compared to other salts due to their extremely large surface area, which provides better contact with microorganisms ${ }^{5}$. The key objective is to prepare the extract of Carica papaya leaves by using Percolation method and to Screen for Phytochemical components of
Carica papaya leaves. To characterize silver nanoparticles (AgNPs) of Carica papaya leaves by UV-Visible spectrophotometry and FT-IR spectral analysis. Finally, to evaluate the Antibacterial activity of crude extracts and silver nanoparticles (AgNPs) synthesized from Carica papaya leaves using the agar well diffusion method.

\section{MATERIALS AND METHODS}

\section{Sample collection}

The Carica papaya plant leaves were collected from the Cumbum Valley, Theni District. Collected leaves were washed with tap water, then rinsed with distilled water, dried, cut into fine pieces and were crushed into fine powder and stored at $37^{\circ} \mathrm{C}$.

\section{Preparation of Carica papaya solvent extract by percolation method}

With the percolation apparatus, $50 \mathrm{~g}$ of dried Carica papaya leave powder was relaxed with ethanol for 40 hours. After transferring, qualitative test was performed to identify the various plant constituents for the stored ethanol extract of Carica papaya residue.

\section{Screening of phytochemical components}

The leaf extracts of Carica papaya were analyzed for the presence of alkaloids, carbohydrates, saponins, phenolic compounds, flavonoids, proteins and amino acids according to the common phytochemical methods such as Mayer's test, Wagner's test, Molisch's test, Benedict's test, Fehling's test, Froth test, Foam test, Ferric chloride test, Alkaline reagent test, Lead acetate test, Xanthoproteic test, Ninhydrin test.

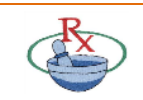




\section{Detection of alkaloids}

Extracts were dissolved individually in dilute Hydrochloric acid and filtered ${ }^{6}$.

\section{Mayer's Test}

Filtrates were treated with Mayer's reagent (Potassium Mercuric lodide). Formation of a yellow colored precipitate indicates the presence of alkaloids.

\section{Wagner's Test}

Filtrates were treated with Wagner's reagent (lodine in Potassium lodide). The formation of a brown / reddish precipitate indicates the presence of alkaloids.

\section{Detection of carbohydrates}

Extracts were dissolved individually in $5 \mathrm{ml}$ distilled water and filtered. The filtrates were used to test for the presence of carbohydrates.

\section{Molisch's Test}

Filtrates were treated with 2 drops of alcoholic $\alpha$-naphthol solution in a test tube. Formation of the violet ring at the junction indicates the presence of carbohydrates.

\section{Benedict's Test}

Filtrates were treated with Benedict 's reagent and heated gently. Orange red precipitate indicates the presence of reducing sugars.

\section{Fehling's Test}

Filtrates were hydrolyzed with diluted Hydrochloric acid, neutralized with alkali and heated with Fehling's A \& B solution. Formation of a red precipitate indicates the presence of reducing sugars.

\section{Detection of saponins}

\section{Froth Test}

Extracts were diluted with distilled water to $20 \mathrm{ml}$ and this was shaken in a graduated cylinder for 15 minutes. A formation of $1 \mathrm{~cm}$ layer of foam indicates the presence of saponins.

\section{Foam Test}

$0.5 \mathrm{gm}$ of the extract was shaken with $2 \mathrm{ml}$ of distilled water. If foam produced persists for ten minutes it indicates the presence of saponins.

\section{Detection of phenols}

\section{Ferric Chloride Test}

Extracts were treated with 3-4 drops of ferric chloride solution. Formation of bluish black color indicates the presence of phenols.

\section{Detection of tannins}

\section{Gelatin Tes}

To the extract, $1 \%$ gelatin solution containing sodium chloride was added. Formation of white precipitate indicates the presence of tannins.

\section{Detection of flavonoids}

\section{Alkaline Reagent Test}

Extracts were treated with a few drops of sodium hydroxide solution. Formation of intense yellow color, which becomes colorless on the addition of dilute acid, indicates the presence of flavonoids.

\section{Lead Acetate Test}

Extracts were treated with a few drops of lead acetate solution. Formation of a yellow color precipitate indicates the presence of flavonoids.

\section{Detection of proteins and amino acids}

\section{Xanthoproteic Test}

The Extracts were treated with a few drops of concentrated Nitric acid. Formation of yellow color indicates the presence of proteins.

\section{Ninhydrin Test}

To the extract, $0.25 \% \mathrm{w} / \mathrm{v}$ ninhydrin reagent was added and boiled for a few minutes. Formation of blue color indicates the presence of amino acid.

\section{Detection of glycosides}

Extracts were hydrolyzed with diluted Hydrochloric acid, and then subjected to test for glycosides.

\section{Legal's Test}

Extracts were treated with Sodium nitroprusside in pyridine and sodium hydroxide. Formation of pink to blood red indicates the presence of cardiac glycosides ${ }^{7}$.

\section{Biosynthesis of silver nanoparticles}

In $250 \mathrm{ml}$ conical flask, $10 \mathrm{ml}$ of aqueous extract of Carica papaya leaves was added to $90 \mathrm{ml}$ of $1 \mathrm{mM}$ aqueous $\mathrm{AgNO}_{3}$ solution and it was incubated with continuous stirring process at $28^{\circ} \mathrm{C}$ for 24 hours. Silver Nitrate is converted into Silver Nanoparticles and this bio reduction is confirmed by the color change from colorless to dark brown and it also indicates shows the formation of silver nanoparticles by the Carica papaya leaf extract. The bio reduction of silver ions in the solution was monitored by sampling the aqueous component after incubation period and Using a UV-Visible Spectrophotometer, absorption maxima was scanned at different wavelengths $(420-500 \mathrm{~nm})$. 


\section{Characterization of biosynthesized silver nanoparticles}

\section{UV-Visible spectrophotometric analysis of silver} nanoparticles

An ELICO SL-159 UV- visible spectrophotometer was used to analyses the spectrometry of biosynthesized silver nanoparticles ${ }^{5}$. The bio-reduction of the $\mathrm{Ag}+$ ions in solution were checked by periodical sampling of aliquots and the UV-Visible spectra of these aliquots were monitored as a function at time of reaction in $430 \& 435$ $\mathrm{nm}$ range operated at a resolution of $1 \mathrm{~nm}$. Distilled water was utilized as a blank ${ }^{1}$. A spectrum of silver nanoparticles was plotted with wave length on $\mathrm{x}$-axis and absorbance on y-axis.

\section{Fourier transform infrared (FT-IR) analysis of silver nanoparticles}

FT-IR spectral analysis was carried out to identify the possible bio molecules responsible for the reduction of the $\mathrm{Ag}^{+}$ions and the capping of the Ag NPs synthesized by Carica papaya extract ${ }^{8}$. The chemical composition of silver nanoparticles was analyzed using a FT-IR spectrometer after bio reduction with silver nitrate. $2 \mathrm{ml}$ of bio synthesized liquid silver nanoparticles were scanned using infrared in the range of $400-4000 \mathrm{~cm}^{-1}$.

\section{Determination of antibacterial activity}

\section{Antibacterial activity - agar well diffusion method}

The agar well diffusion method is widely used to evaluate the antimicrobial activity of plant extracts ${ }^{9,10}$. Similarly, to the procedure used in disk-diffusion method, the MullerHinton agar plate surface is inoculated by spreading a volume of the microbial inoculum over the entire agar surface. Carica papaya crude extract solution $(25,50,75$ $\& 100 \mu \mathrm{L}$ ) and AgNPs synthesized extract solution at desired concentration is introduced into the hole (diameter 6 to $8 \mathrm{~mm}$ ) of agar. This hole is made aseptically with a sterile cork border ${ }^{11}$. Then, agar plates are incubated under suitable conditions depending upon the test microorganism. The antimicrobial agent diffuses in the agar medium and inhibits the growth of the microbial strain tested

\section{RESULTS AND DISCUSSION}

In our study, Phytochemical activities of Papaya leaves were evaluated under in vitro condition. Alkaloids, Carbohydrates, Saponins, Phenols, Flavonoids, Tannins, Cardiac glycosides, Proteins and Amino acids are the compounds found in the phytochemical analysis of the papaya leaf (Table 1). These findings can be attested to the good antimicrobial agent on the different test organism. Comparing to other solvent extracts, the ethanol extracts exhibited a higher inhibitory activity of the test organisms due to its different polarities and different degrees of solubility for the various phytoconstituents ${ }^{\mathbf{1 2}}$. The pharmacological properties of Carica papaya lie in the various chemical constituents. Few important Phytochemicals found in Carica papaya are Lycopene, Betacarotinoid, Benzylisothyocynate, Betacryptoxanthin, Benzylglucosinolate, chlorogenic acid, caffeic acid, protocatachuic acid, Quercetin ${ }^{13}$. Papaya rich in tannins possesses antibacterial property which allows them to react with proteins to form stable water-soluble compounds damaging their cell walls and kills bacteria ${ }^{14}$.

Table 1: Phytochemical screening of Carica papaya leaf extract

\begin{tabular}{|c|c|c|}
\hline S No. & Phytochemicals & $\begin{array}{c}\text { Presence of Phytochemical in ethanolic } \\
\text { extract of Carica papaya }\end{array}$ \\
\hline 1. & Alkaloids & + \\
\hline 2. & Carbohydrates & + \\
\hline 3. & Saponins & + \\
\hline 4. & Phenols & + \\
\hline 5. & Tannins & + \\
\hline 6. & Flavonoids & + \\
\hline 7. & Proteins and Amino acids & + \\
\hline 8. & Glycosides (Cardiac glycosides) & + \\
\hline 9. & Steroids & - \\
\hline 10. & Triterpenoids & + \\
\hline
\end{tabular}

(+): Present; (-): Absent

Karpain, a chemical substance which kills microorganisms that often interfere with the digestive function ${ }^{15}$. These bioactive compounds are used mainly because they are the derivatives of natural plant sources. It would also be 
observed that the fresh leaves Carica papaya silver nanoparticles exhibited better antimicrobial potentials than the dried leaves Carica papaya silver nanoparticles ${ }^{16}$. Nano materials had proven to be the most efficient mode of drug delivery in modern Medicine. Other than physical and chemical methods, the Development of green synthesis nanoparticles was cost effective, eco-friendly, and can be easily scaled up for large scale synthesis of nanoparticles ${ }^{17}$.

Due to the small size of nanoparticles, which may confer the ability to penetrate the cells/microbes and execute the bactericidal property. Surface Plasmon Resonance (SPR) caused the color change in bio-reduction of silver Nanoparticles ${ }^{5}$. SPR is the resonant oscillation of conduction electrons at the interface between a negative and positive permittivity materials stimulated by incident light. Sometimes the color changed by metallic nanoparticles is due to the coherent excitation of all free electrons which are released by phenolic compounds present in the extract ${ }^{18}$.

Carica papaya leaf extract's FTIR spectrum displays the presence of AgNPs with transmission peaks at 536.21, 1639.49 and $3456.44 \mathrm{~cm}^{-1}$ respectively (Figure 1). The absorption peak at $3456.44 \mathrm{~cm}$-1corresponded to $\mathrm{OH}$ groups present in alcohols and phenolics; band appearing at $1639.49 \mathrm{~cm}^{-1}$ could be due to amide bond coming from the carbonyl group of a protein, absorption peak at $536.21 \mathrm{~cm}-1$ appear from $\mathrm{C}-\mathrm{H}$ stretch and aromatic (Figure 1).

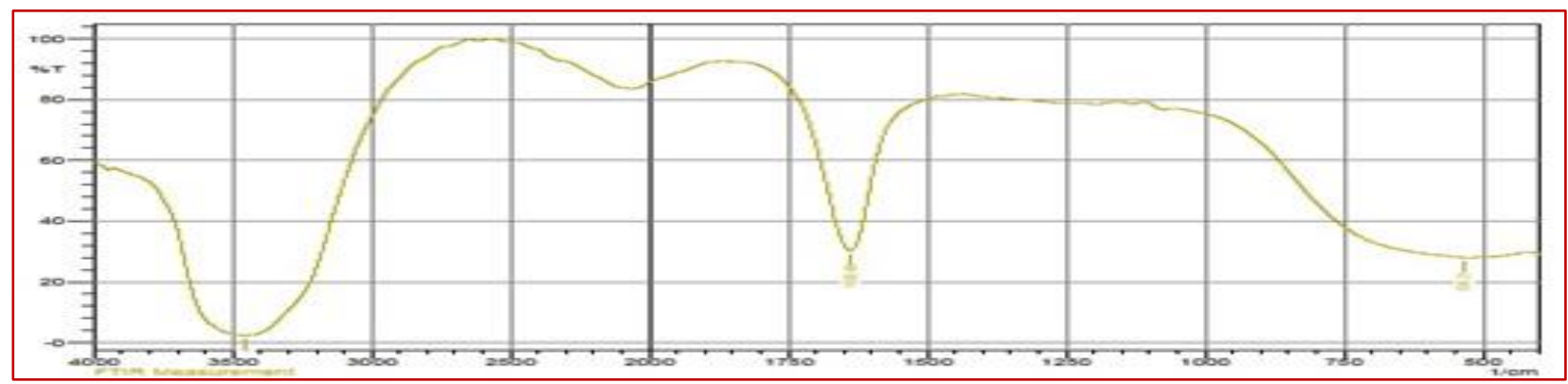

Figure 1: FT-IR spectra of silver nanoparticles synthesized from Carica papaya leaf extract

The antibacterial activity of crude extract was studied against the pathogenic microbial strain such as Escherichia coli, Enterococcus spp, Klebsiella spp, Staphylococcus spp using the agar well diffusion method.

The effective zone of inhibition was observed in crude extract against Staphylococcusspp, Klebsiella spp, Escherichia coli, Enterococcus spp while increasing the concentration $(25,50,75$ and $100 \mu \mathrm{l}$ ) (Figure 2-5). The highest activity of $22 \mathrm{~mm}$ diameter of zone of inhibition was obtained against Staphylococcusspp, and $20 \mathrm{~mm}$ diameter of zone of inhibition was observed against Klebsiella spp and Escherichia coli, and 19mm diameter of zone of inhibition was observed against Enterococcusspp.The synthesized silver nanoparticles derived from the papaya leaf extract exhibited an excellent antibacterial activity against both gram positive and gramnegative bacteria. The results suggest that silver nanoparticles undergo an interaction with bacterial cell and displayed the strong bactericidal action against Escherichia coli, Enterococcus spp, Klebsiella spp,
Staphylococcus spp. The highest activity of $18 \mathrm{~mm}$ diameter of zone of inhibition was obtained against Staphylococcus $\mathrm{spp}$, and $17 \mathrm{~mm}$ diameter of zone of inhibition against Klebsiella spp, and $15 \mathrm{~mm}$ diameter of zone of inhibition was obtained against Escherichia coli, and $13 \mathrm{~mm}$ diameter of zone of inhibition against Enterococcusspp. Among the evaluation of Gram positive and Gram-negative bacteria, Gram negative bacteria were more susceptible to this extract, however, is at disparity with an earlier report indicating that plant extracts are more active against Gram positive bacteria. The Zone of inhibition produced by the synthesized silver nanoparticles by destructing the cell wall and ceasing the cell permeability, formation of free radicals, inactivating important enzymes, interaction of silver nanoparticles with DNA and interruption of DNA replication and translation and by dephosphorylating the tyrosine residues on peptides inhibiting the signal transduction and growth in bacteria ${ }^{19}$. 


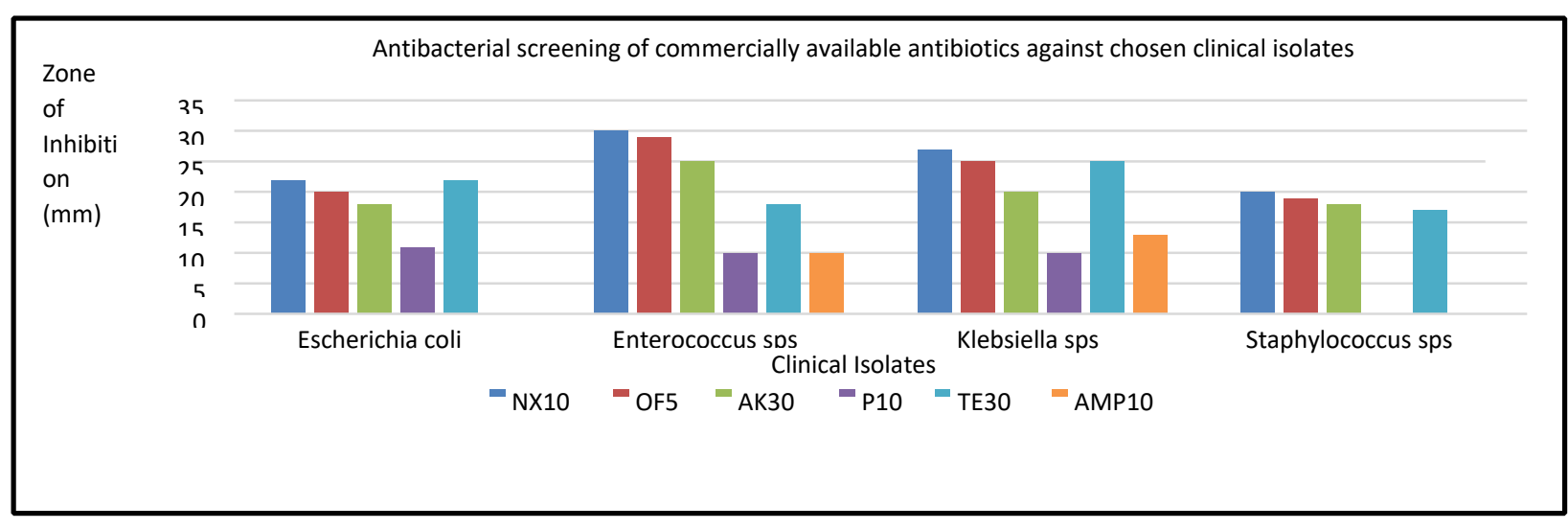

Figure 2: Antibacterial screening of commercially available antibiotics against chosen clinical isolates

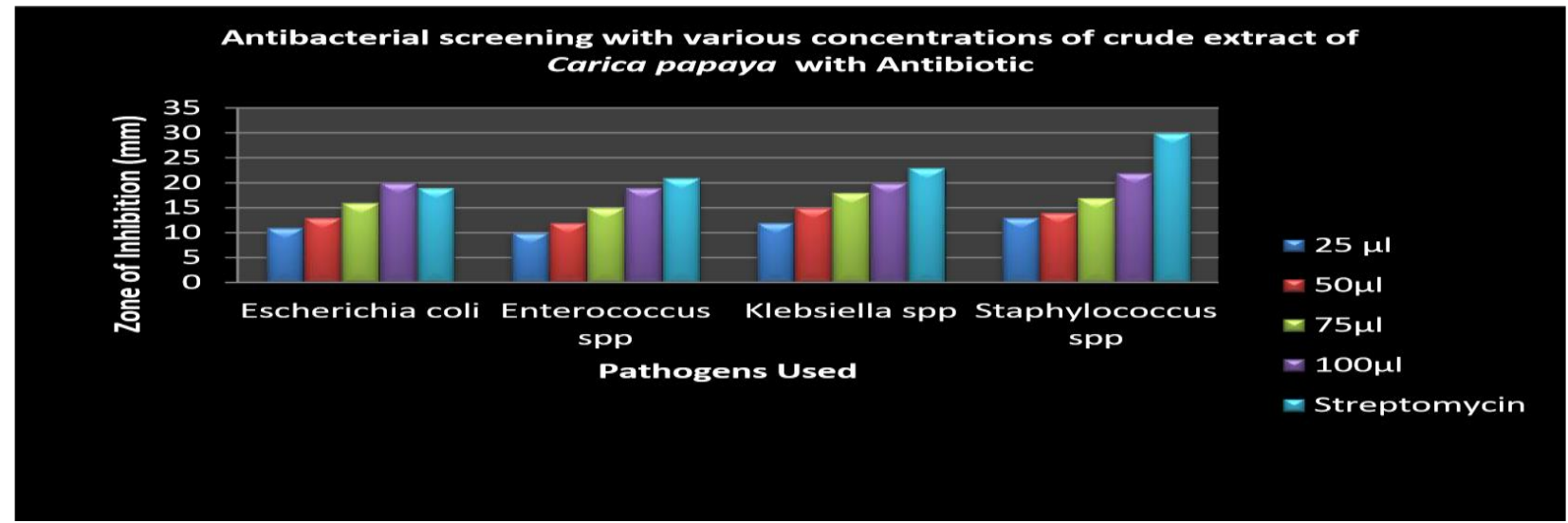

Figure 3: Antibacterial screening of crude Carica papaya leaf extract against chosen clinical isolates with antibiotic

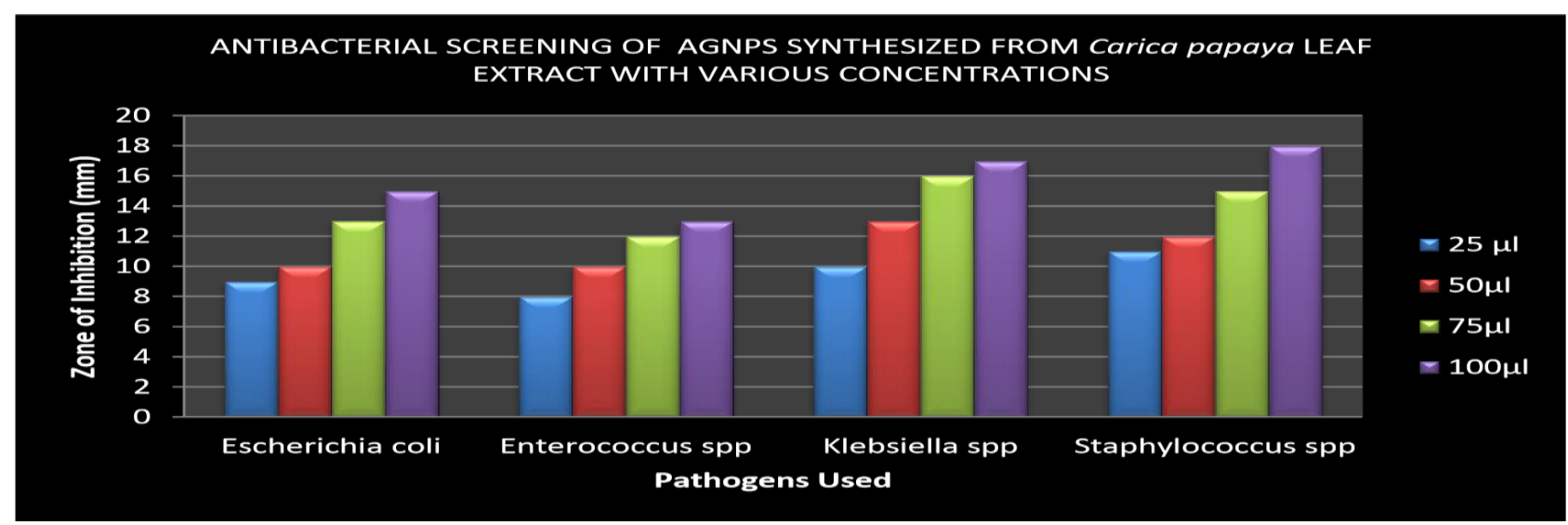

Figure 4: Antibacterial screening of AgNPs synthesized Carica papaya leaf extract (Ethanol)

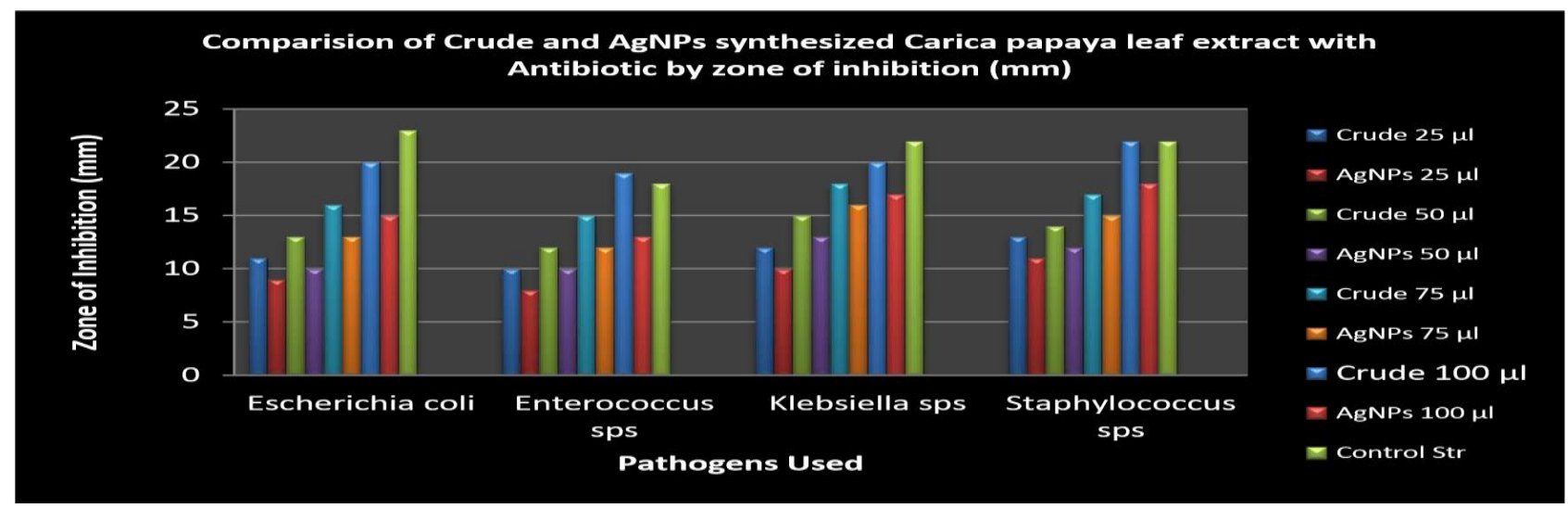

Figure 5: Antibacterial activity-comparison of crude and AgNPs synthesized Carica papaya leaf extract (Ethanol) with antibiotic

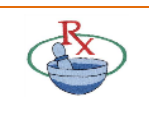




\section{CONCLUSION}

Even though this study found that crude extract is more potent than biosynthesized silver nanoparticles. Silver nanoparticles synthesized with identified Phytochemical constituent will show best results. Further research, exploration is needed to identify the particular constituent's biosynthesis to produce novel and costeffective Nano based antimicrobial agents. Carica papaya leaves can be developed into a promising drug candidate for biomedical applications. Large surface area of Silver nanoparticles is one of the major factors for its efficient biological property, which establishes better contact with microorganisms than any other salts.

The silver nanoparticles get attached to the cell membrane and also penetrated inside the bacteria. The bacterial membrane contains sulfur containing proteins and the silver nanoparticles get attached to these proteins in the cell as well as and the phosphorus containing compounds like DNA ${ }^{20}$.

Great Push toward silver nanoparticles for delivering drugs will be seen in future due to the ease delivery in drug delivery $^{\mathbf{2 1}}$. The usage of medicinal plant materials for the synthesis of nanoparticles has been revolutionized in recent years and could serve as an alternative for antibiotics $^{22}$.

\section{REFERENCES}

1. Banerjee S, Loza K, Meyer-zaika M, Prymak O, Epple M. Structural evolution of silver nanoparticles during wet-chemical synthesis. Chem. Mater., 2014; 26(2): 951-957.

2. Lansdown AB. Silver in health care: antimicrobial effects and safety in use. Curr Probl Dermatol. 2006; 33: 17-34.

3. Santana LF, Inada AC, Espirito Santo BLSD, Filiú WFO, Pott A, Alves FM, Guimarães RCA, Freitas KC, Hiane PA. Nutraceutical Potential of Carica papaya in Metabolic Syndrome. Nutrients. 2019; 16: 11(7): 1608.

4. Cyril Aymonier, Ulf Schlotterbeck, Lydie Antonietti, Philipp Zacharias, Ralf Thomann, Joerg C.Tiller and Stefan Mecking . Hybrids of silver nanoparticles with amphiphilic hyperbranched macromolecules exhibiting antimicrobial properties. Chem. Commun., 2002; 3018-3019.

5. Rajkiran RB, Veera BN, Pratap RK. Green synthesis and characterization of Carica papaya leaf extract coated silver nanoparticles through X-ray diffraction, electron microscopy and evaluation of bactericidal properties. Saudi Journal of Biological Sciences. 2015; 22: 637-644.

6. Santhi $K$ and Sengottuvel R. Qualitative and Quantitative Phytochemical analysis of Moringa concanensis Nimmo. Int. J. Curr. Microbiol. App. Sci., 2016; 5(1): 633-640.

7. Rajasudha $V$ and Manikandan R. Phytochemical screening and Highperformance liquid chromatography (HPLC) profile of different extracts of Euphorbia hirta (Linn). Journal of Pharmacognosy and Phytochemistry 2019; 8(1): 45-50.

8. Quan V. Vuong, Sathira Hirun, Tiffany L.K. Chuen, Chloe D. Goldsmith, Shane Murchie, Michael C. Bowyer, Phoebe A. Phillips \& Christopher J. Scarlett. Antioxidant and anticancer capacity of saponin-enriched Carica papaya leaf extracts. International Journal of Food Science and Technology. 2015; 50: 169-177.

9. Lidiani F. Santana, Aline C. Inada, Priscila A. Hiane. Nutraceutical Potential of Carica papaya in Metabolic Syndrome, Nutrients. 2019; 11(7): 1608.

10. Udoh P, Essien I, Udoh F. Effects of Carica papaya (paw paw) seeds extract on the morphology of pituitary-gonadal axis of male Wistar rats. Phytother. Res. 2005; 19(12): 1065-1068.

11. Mounyr Balouiri, Moulay Sadiki, and Saad Koraichi Ibnsouda. Methods for in vitro evaluating antimicrobial activity: A review. J. Pharm. Anal. 2016; 6(2): 71-79.

12. Swathi G, Sridevi A, Sandya A, Praveen B, Narasimha G. Biosynthesis, characterization and antibacterial activity of silver nanoparticles by soil fungi Pencillium sps. Int. J. Drug. Deliv. 2014; 6: 165-171.

13. Sheikh Fauziya and R Krishnamurthy, Papaya (Carica papaya): source material for anticancer. CIBTech Journal of Pharmaceutical Sciences. 2013; 2(1): 25-34.

14. Baskaran C, Ratha V, Velu S, Kumaran K. The efficacy of Carica papaya leaf extract on some bacterial and a fungal strain by well diffusion method. Asian Pacific Journal of Tropical Disease. 2012; 658-662.

15. Aravind G, Debjit B, Duraivel S, Harish G, Traditional and medicinal uses of Carica papaya. J. Med. Plants stud. 2013; (1): 7-15.

16. Reshma S. Konjari, Anju A. Jacob, Jayanthi S, Ramalingam C, Anita S. Ethiraj. Investigation of Biogenic silver nanoparticles green synthesized from Carica papaya. International Journal of pharmacy and pharmaceutical sciences. 2015; 7(3): 107-110.

17. Khadeeja Parveen, Viktoria Banse and Lalita Ledwani, Green synthesis of nanoparticles: Their advantages and disadvantages. AIP Conference Proceedings. 2016; 1724: 020048.

18. Liu YC, Lin LH. New pathway for the synthesis of ultrafine silver nanoparticles from bulk silver substrates in aqueous solution by sono-electrochemical methods. Electrochem Commun. 2004; 6(11): 1163-1168.

19. Khan Z, Al-Thabsiti SA, Obaid AY, Al-Youbi AO. Preparation and characterization of silver nanoparticles by chemical reduction method. Colloids and Surfaces B: Biointerfaces. 2011; 82(2): 513517.

20. Balaram Das, Sandeep Kumar Dash, Debasish Mandal,Totan Ghosh, Sourav Chattopadhyay, Satyajit Tripathy, Sabyasachi Das, Sankar Kumar Dey, Debasis Das, Somenath Roy. Green synthesized silver nanoparticles destroy multidrug resistant bacteria via reactive oxygen species mediated membrane damage. Arabian Journal of Chemistry. 2017; 10(6): 862-876.

21. Varahalarao Vadlapudi, Mohan Behara, M. Nagalakshmi Devamma. Green Synthesis and biocompatibility of nanoparticles. RASĀYAN J. Chem. 2014; 7(3): 219-223.

22. Okwu DE, Ekeke $O$, Phytochemical screening and mineral composition of chewing sticks in South Eastern Nigeria, Global. J. Pure Appl. Sci., 2003(9): 235-238.

Source of Support: The author(s) received no financial support for the research, authorship, and/or publication of this article.

Conflict of Interest: The author(s) declared no potential conflicts of interest with respect to the research, authorship, and/or publication of this article.

For any question relates to this article, please reach us at: editor@globalresearchonline.net

New manuscripts for publication can be submitted at: submit@globalresearchonline.net and submit_ijpsrr@rediffmail.com 